\title{
Anterolateral ligament of the knee, fact or fiction?
}

\author{
Volker Musahl ${ }^{1}$ - Ata A. Rahnemai-Azar ${ }^{1}$. Carola F. van Eck ${ }^{1}$. \\ Daniel Guenther ${ }^{2} \cdot$ Freddie H. Fu ${ }^{1}$
}

Published online: 22 December 2015

(C) European Society of Sports Traumatology, Knee Surgery, Arthroscopy (ESSKA) 2015

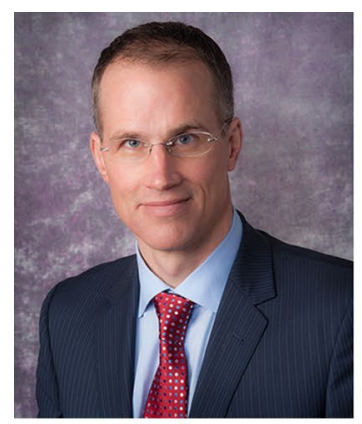

Volker Musahl

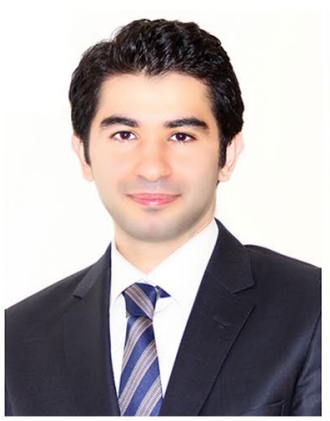

Ata A. Rahnemai-Azar

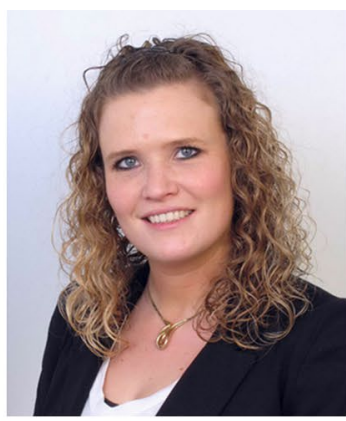

Carola F. van Eck

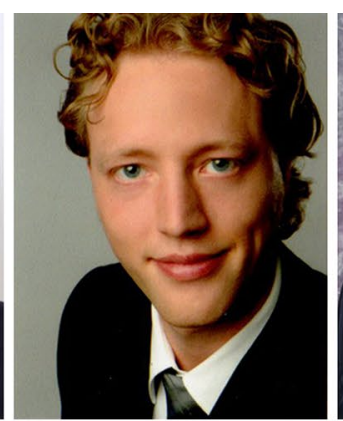

Daniel Guenther

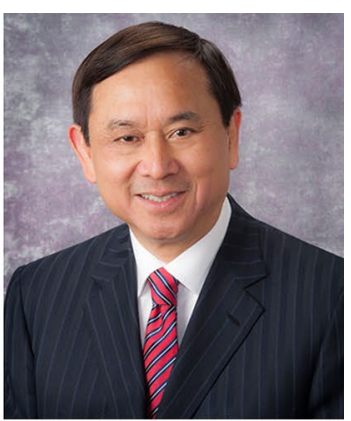

Freddie H. Fu
A heated debate is ongoing regarding the anatomy of the anterolateral capsule of the knee. Current literature provides a multitude of descriptions. Researchers have argued that the capsule contains a true ligament, while others suggest it merely displays a thickening; yet others fail to show any distinguishable capsular structures. Given the recent surge in the literature on the anterolateral capsule of the knee, it is of great importance to be meticulous in evaluating every aspect of it, including the anatomy, histology, biomechanics, kinematics and clinical implication prior to recommending on its repair or reconstruction.

While performing anatomic dissections on 24 different animal species, we have consistently found a double lateral collateral ligament (LCL) in three types of primates;

Freddie H. Fu

ffu@upmc.edu

1 Department of Orthopaedic Surgery, University of Pittsburgh, Kaufman Building Suite 1011, 3471 Fifth Avenue, Pittsburgh, PA 15213, USA

2 Trauma Department, Hannover Medical School (MHH), Carl-Neuberg-Str. 1, 30625, Hannover, Germany however, an anterolateral ligament (ALL) was never seen in any of the examined species. This suggests a negative selection against this feature in our own evolution. We have also dissected several fetuses aged 18-22 weeks, and again no distinguishable anterolateral ligament was identified within the capsule. When evaluating the macroscopic anatomy, histology and radiology of the anterolateral capsule in adult human cadaveric specimens, only $30 \%$ of the specimens showed a discrete capsular thickening of 2-4 mm on magnetic resonance imaging (MRI), much thinner than, for example, the LCL. During arthroscopic trans-illumination of these same specimens, no thickening of the anterolateral capsule was seen. Interestingly, on further analysis, internal rotation and flexion of the knee caused a fold in the anterolateral capsule, mimicking a thickening. Histology of this capsular thickening was performed and compared with that of the LCL. The LCL showed a clear linear alignment of collagen fibres, while the anterolateral capsule showed some alignment but not pronounced enough to constitute a true ligament [3].

In our experience of evaluating the anatomy of the anterolateral capsule in more than 150 patients with an 
anterior cruciate ligament (ACL) injury during arthroscopy, no overt pathology of the anterolateral capsule was observed, nor was any thickening appreciated. Tensile testing of the anterolateral capsule of the knee showed that the anterolateral capsule has 4 times less stiffness, 5 times less load to failure and twice the ultimate elongation compared to other knee ligaments, which fails to support a ligamentous function of this structure. During a simulated pivot shift test using a robotic testing system, the contribution of this section of the capsule to the knee stability was negligible.

When evaluating knee kinematics after anatomic ACL reconstruction using dynamic stereo $\mathrm{X}$-ray, several researchers have shown that subjects had increased tibial external rotation in the operated knee. This would suggest that an additional anterolateral restraint might further worsen the abnormal kinematics by increasing the external rotation. Moreover, reconstruction of the ALL has not been shown to restore rotational laxity [5]. In fact, extraarticular procedures have been shown to over-constrain the knee resulting in a decrease in the internal rotation after a combined ACL reconstruction and extra-articular tenodesis $[1,2]$.

The Segond fracture has been suggested as the bony equivalent of an ALL rupture. However, Segond fractures are relatively rare, and the presence of one has not been linked to an increase in rotational laxity in the ACL-injured knee.

It appears that many questions regarding the anterolateral capsule of the knee remain. Future studies are needed to better evaluate the structural properties of the anterolateral capsule, the role of anterolateral capsular injuries on the stability of the knee, how to best restore the function of the anterolateral capsule [4] and the effect of extraarticular repairs or reconstruction on the outcome after
ACL surgery. Until these questions are answered, perhaps the focus should remain on restoring the native anatomy. If an anatomic structure is torn, the goal should be to reconstruct its anatomy to as close to native as possible. If an ACL reconstruction fails, we should first determine why it has failed, focusing on graft choice, size, bony morphology, reconstruction method and tunnel placement before looking for the cause in the anterolateral capsule structures. After all, providing individualized care to ensure the best potential for a successful outcome for our patients should be our main goal.

\section{References}

1. Arilla F, Guenther D, Yacuzzi C, Rahnemai-Azar A, Fu FH, Debski R, Musahl V (2015) Effects of anterolateral capsular injury and extra-articular tenodesis on knee kinematics during physical examination. Paper presented at the American Orthopaedic Society for Sports Medicine, Orlando

2. Branch T, Lavoie F, Guier C, Branch E, Lording T, Stinton S, Neyret P (2015) Single-bundle ACL reconstruction with and without extra-articular reconstruction: evaluation with robotic lower leg rotation testing and patient satisfaction scores. Knee Surg Sports Traumatol Arthrosc 23(10):2882-2891

3. Dombrowski ME, Costello JM, Ohashi B, Murawski CD, Rothrauff BB, Arilla FV, Friel NA, Fu FH, Debski RE, Musahl V (2015) Macroscopic anatomical, histological and magnetic resonance imaging correlation of the lateral capsule of the knee. Knee Surg Sports Traumatol Arthrosc. doi:10.1007/ s00167-015-3517-8

4. Kittl C, Halewood C, Stephen JM, Gupte CM, Weiler A, Williams A, Amis AA (2015) Length change patterns in the lateral extra-articular structures of the knee and related reconstructions. Am J Sports Med 43(2):354-362

5. Spencer L, Burkhart TA, Tran MN, Rezansoff AJ, Deo S, Caterine S, Getgood AM (2015) Biomechanical analysis of simulated clinical testing and reconstruction of the anterolateral ligament of the knee. Am J Sports Med 43(9):2189-2197 